\title{
Modelling nitrogen and phosphorus export by the Pearl River in China 1970-2050
}

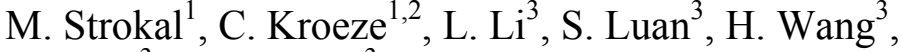 \\ S. Yang ${ }^{3} \&$ Y. Zhang \\ ${ }^{1}$ Environmental Systems Analysis Group, \\ Wageningen University, The Netherlands \\ ${ }^{2}$ School of Science, Open University of The Netherland, The Netherlands \\ ${ }^{3}$ Peking University, Nanshan District, P.R. China
}

\begin{abstract}
China is a country with a rapid economic development and fast population growth. This is causing environmental pollution. Eutrophication has been a problem in the coastal waters of southern China since the $1970 \mathrm{~s}$. This is a result of increased nitrogen $(\mathrm{N})$ and phosphorus $(\mathrm{P})$ inputs from rivers such as the Pearl River (Zhujiang). The Pearl River is the third largest river in China. It serves as an important water supplier for irrigation and human water consumption. Human activities on land, however, have increased the nutrient content of the Pearl River water considerably. The objective of our study is to quantify the relative contribution of the anthropogenic and non-anthropogenic sources of dissolved inorganic $\mathrm{N}$ and $\mathrm{P}$ export by the Pearl River to coastal seas. We describe a method to model dissolved $\mathrm{N}$ and $\mathrm{P}$ export at the sub-basin scale. Results indicate that in 2000 about $90 \%$ of the dissolved $\mathrm{N}$ and $\mathrm{P}$ inputs exported by the Pearl River to the coastal waters were from anthropogenic sources (e.g. agriculture, sewage, and biological $\mathrm{N}_{2}$-fixation by agricultural crops). In the future the relative share of anthropogenic sources may increase. We show that nutrient inputs from land to rivers vary among sub-basins. We conclude that modelling and scenario analyses may support the formulation of effective strategies to reduce $\mathrm{N}$ and $\mathrm{P}$ export by the Pearl River, and thus to effective management of coastal eutrophication in the coming decades.
\end{abstract}

Keywords: nutrient modelling, $N$ and $P$ export, the Pearl River, China. 


\section{Introduction}

Coastal eutrophication is a worldwide environmental problem [1-3]. Also in the Chinese coastal waters events of eutrophication and hypoxia have occurred since the 1970s [2-5]. Coastal eutrophication typically occurs when coastal waters receive large amounts of nutrients such as nitrogen $(\mathrm{N})$ and phosphorus $(\mathrm{P})$ [3]. Increased concentrations of these nutrients in coastal waters may generate harmful algal blooms (of non-siliceous algae) and lead to hypoxia (oxygen depletion) [6-8].

Increased $\mathrm{N}$ and $\mathrm{P}$ inputs to coastal waters largely result from human activities on land $[2,9,10]$ such as agriculture [11] and urbanisation [12]. China is a country with a rapid economic development and a fast growing population [13-19]. For example, the number of cities in China more than quadrupled and the urban population increased by over 20 times between the 1950s and 2008 [17]. The consumption of synthetic $\mathrm{N}$ fertilizers also quadrupled between the 1980s and 2005 [20] indicating intensifying agriculture. This contributed to increased $\mathrm{N}$ and $\mathrm{P}$ inputs to Chinese rivers such as the Pearl River and consequently to coastal waters $[21,22]$.

The Pearl River (the Zhujiang in Chinese) is the third largest river in China. Its drainage basin covers about 440 thousand $\mathrm{km}^{2}$ (see Methodology). It is located in the southern part of China and serves as an important water supplier for irrigation and human water consumption [23]. Nutrient pollution in the coastal waters, however, has become a serious problem because of the human pressure $[5,24]$. The associated eutrophication is causing environmental (e.g. biodiversity loss) and economic damages (e.g. less fish and thus less profits) [5].

A better understanding of the sources of $\mathrm{N}$ and $\mathrm{P}$ in the Pearl River water would support the reduction or prevention of further coastal eutrophication. So far, however, no systematic analyses of nutrients and their sources in the Pearl River basin have been published. Some analyses of nutrients in coastal waters have been published [24-27], but these are limited to specific areas within the Pearl River estuary and to specific nutrient sources. Some studies cover the entire river basin [28-31], however, without a focus on the sources of nutrients.

This objective of this study, therefore, is to quantify the relative contributions of the sources of $\mathrm{N}$ and $\mathrm{P}$ export by the Pearl River to coastal seas for the period 1970-2050. We will do this by considering sub-basin characteristics (e.g. human activities, nutrient retentions and hydrology). In this study we distinguish between anthropogenic and non-anthropogenic sources of nutrients (see Methodology). The outcomes of this study may help to formulate strategies to reduce $\mathrm{N}$ and $\mathrm{P}$ loads to seas in southern China, and thus to reduce coastal eutrophication.

\section{Methodology}

\subsection{The Pearl River basin}

We modelled the $\mathrm{N}$ and $\mathrm{P}$ export by the Pearl River at the sub-basin scale for the period of 1970-2050. To this end, six sub-basins of the Pearl River were 
identified based on the literature [23, 28, 30-32]. These sub-basins are Yujiang, and Liujiang (up-stream), Xijiang, and Beijiang (middle-stream), and Dongjiang and Zhujiang delta (down-stream). Figure 1 shows the locations of these subbasins. One-third of the Pearl River basin is considered up-stream sub-basins here. Half of the basin area is middle-stream sub-basins and the rest $(20 \%)$ are the down-stream sub-basins (see Figure 1).
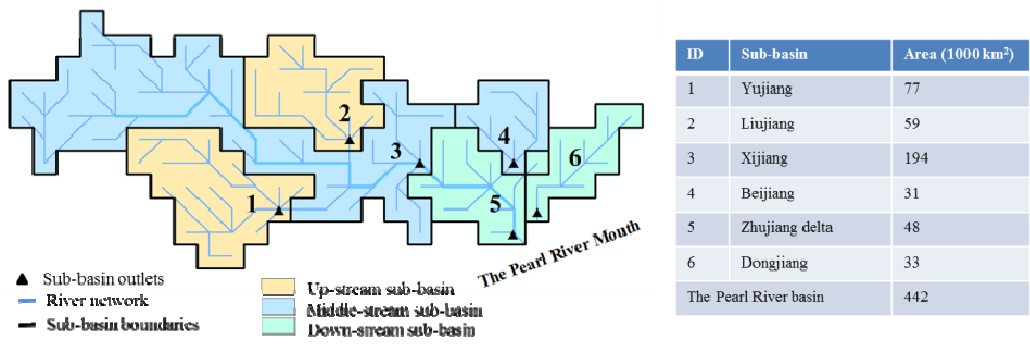

Figure 1: The Pearl River basin and its sub-basins (indicated by ID number). Boundaries of the sub-basins were delineated using the Simulated Topological Network (STN-30 v6.01) [33, 34].

\subsection{Modelling nitrogen and phosphorus export}

Our research focuses on dissolved inorganic forms of $\mathrm{N}$ and $\mathrm{P}$ (DIN and DIP). These are readily bioavailable forms of $\mathrm{N}$ and $\mathrm{P}$, and thus directly contribute to eutrophication [35].

As mentioned above, we distinguish between anthropogenic and nonanthropogenic sources of $\mathrm{N}$ and $\mathrm{P}$ in the Pearl River. Anthropogenic sources include a number of diffuse sources: animal manure excretion (for DIN, DIP), synthetic fertilizer use (DIN, DIP), biological $\mathrm{N}_{2}$-fixation by agricultural crops, atmospheric N-deposition on agricultural land (DIN) and P-weathering (DIP) in agricultural areas. In addition, there are anthropogenic point sources including sewage inputs of human waste (DIN, DIP) and detergents (DIP). Nonanthropogenic diffuse sources include biological $\mathrm{N}_{2}$-fixation, atmospheric $\mathrm{N}$ deposition (for DIN) and P-weathering (DIP) in non-agricultural areas. These two main groups of nutrient sources are included in the Global NEWS-2 (Nutrients Export from WaterSheds, updated version 2) model [10, 34]. This model can be used to quantify the relative shares of these sources in river export of nutrients for past $(1970,2000)$ and future $(2030,2050)$ years.

We quantified the contributions of the nutrient sources in two steps. The first step is to quantify inputs of DIN and DIP to the outlet of each sub-basin by source. To this end, we followed the approach of the Global NEWS-2 model [34]:

DIN and DIP export at the sub-basin outlet from by source (ton $\mathrm{km}^{-2}$ ) $=$ DIN and DIP inputs to rivers from each source (ton $\left.\mathrm{km}^{-2}\right) *$ river export fraction $(0-1)$ 
Detailed descriptions of this approach are provided by Mayorga et al. [34]. In brief, nutrient inputs from land to rivers by source (anthropogenic and nonanthropogenic) are modelled based on a mass-balance approach, except for weathering of P-contained minerals. The latter is quantified using an exportcoefficient approach. The mass-balance approach implies quantification of the net $\mathrm{N}$ and $\mathrm{P}$ inputs to land from the diffuse sources and multiplying these inputs by the export watershed fraction, which describes the nutrient retention within the watershed (land) [11, 34]. The export-coefficient approach implies that nutrient inputs to rivers are calculated as a function of annual runoff from land to streams. For anthropogenic point sources, DIN and DIP inputs to surface waters are quantified using fractions of $\mathrm{N}$ and $\mathrm{P}$ removal during sewage treatment, the fraction of the population connected to sewage systems and the amount of human waste (for both DIN, DIP) and detergents (for DIP) produced by the urban population. These are multiplied by the fraction of elemental $\mathrm{N}$ and $\mathrm{P}$ inputs to rivers that are DIN or DIP $[12,34]$. Table 1 presents the DIN and DIP inputs to rivers by source.

In the Global NEWS-2 model, the river export fractions describe the $\mathrm{N}$ and $\mathrm{P}$ removal from and retention within the river system. This fractions account for: (1) consumptive water use (generic for DIN and DIP), (2) N and P retention in dammed reservoirs (for DIN, DIP) and in the river (e.g. denitrification for DIN only) [34]. We improved the Global NEWS-2 approach by including $\mathrm{P}$ retention/losses in the river system for DIP (e.g. accumulation of DIP in sediments by iron binding).

The Global NEWS-2 model was validated for large Chinese rivers, including the Pearl River [21]. The validation results indicate an acceptable match between observed DIN and DIP river export [36] and modelled values [34]. These results give us confidence in the model approach to quantify DIN and DIP inputs to the outlets of the sub-basin.

The second step in our study is to quantify inputs of DIN and DIP exported by the Pearl River to coastal waters by source. We account for nutrient transport from sub-basin to sub-basin. The DIN and DIP export by up-stream sub-basins (ton $\mathrm{km}^{-2}$ ) is multiplied by river export fractions of the middle- and down-stream sub-basins to calculate how much of this DIN and DIP is exported to the coastal seas. Likewise, the DIN and DIP export by middle-stream sub-basins (ton $\mathrm{km}^{-2}$ ) is multiplied by river export fraction of the down-stream sub-basins. This way we take into account DIN and DIP losses and retentions through the river network of the entire Pearl River basin. The sum of DIN and DIP inputs at the Pearl River mouth from all sub-basins is the total input to the coastal seas.

The model inputs were derived from various sources [11, 12, 34, 37, 38]. Model inputs for diffuse sources are from Bouwman et al. [11], for point sources from Van Drecht et al. [12], and for climate and hydrology from Fekete et al. [37]. These inputs are for past and future years. In this study future trends in DIN and DIP export are based on storylines of the Global Orchestration (GO) scenario of the Millennium Ecosystem Assessment (MEA). These storylines were quantitatively interpreted by Bouwman et al. [11], Van Drecht et al. [12] and Fekete et al. [37] to produce input databases for the Global NEWS-2 model. 


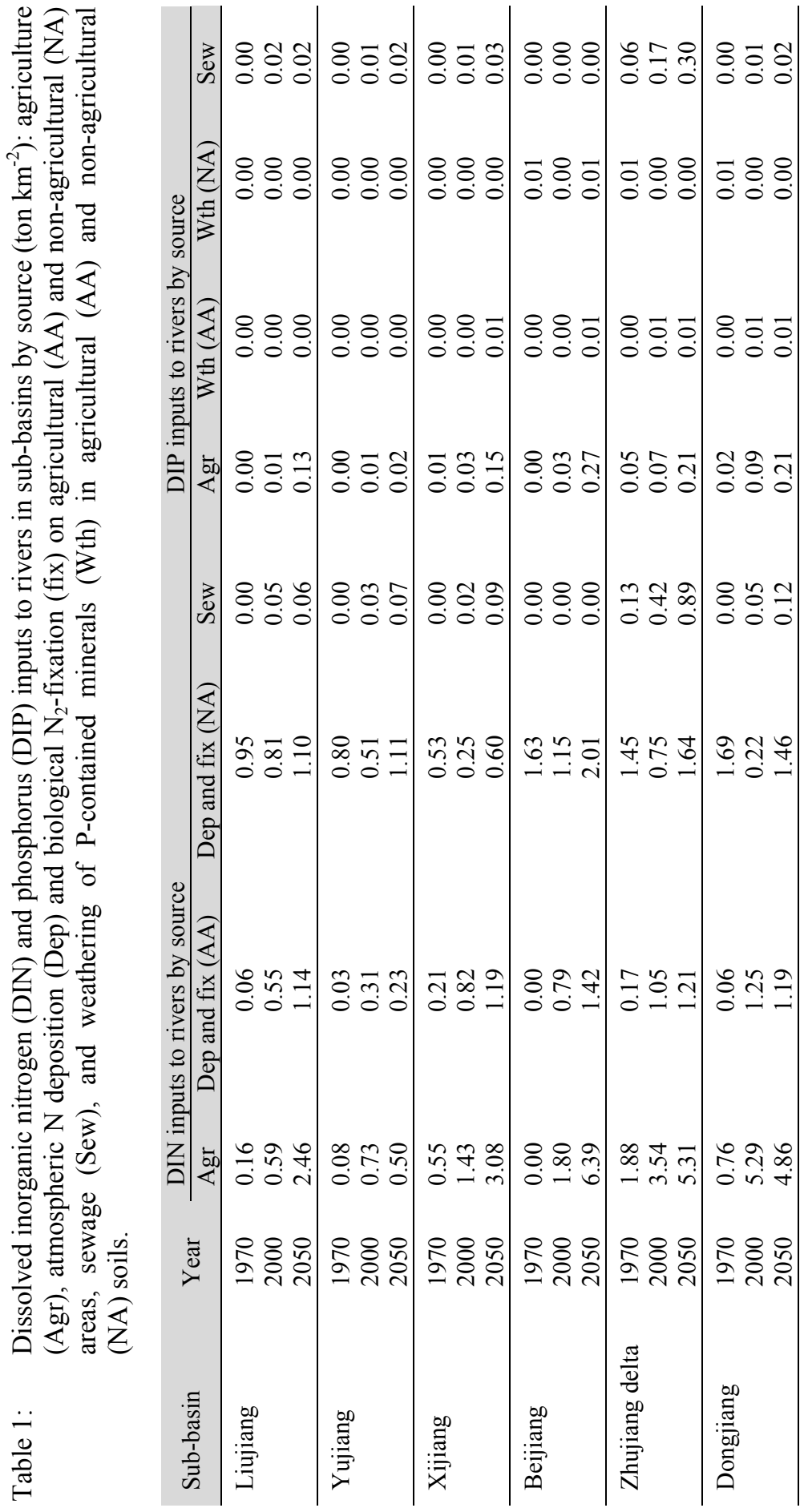


GO assumes a globalized world with a reactive approach to manage environmental problems [10,39, 40]. Details on the scenario are presented by Seitzinger et al. [10], Alcamo et al. [39] and Carpenter et al. [40]. Data regarding dams and their associated reservoirs are from Lehner et al. [38] and Lehner et al. [41].

\section{DIN and DIP export by the Pearl River in 1970-2050}

\subsection{DIN export}

Between 1970 and 2000 DIN inputs exported by the Pearl River to the coastal waters increased by about $60 \%$. This is because of increased anthropogenic inputs during this period (Figure 2).

In 1970 about half of the total DIN export (around 0.10 ton $\mathrm{km}^{-2}$ ) to the coastal waters was from anthropogenic sources (bar charts in Figure 2). These sources include human waste (point source), agriculture, atmospheric Ndeposition and biological $\mathrm{N}_{2}$-fixation by agricultural crops (diffuse sources). In 2000 , almost $90 \%$ of the total DIN export by the Pearl River to the coastal waters was from these anthropogenic sources. We calculated the increased DIN inputs to rivers by sub-basin during the period 1970-2000 (pie charts in Figure 2). The DIN inputs from land to rivers in the down-stream sub-basins exceed those in up-stream basins (maps in Figure 2). This can be explained by more human activities in down-stream than in up-stream basins. Other studies [24-26] confirm that down-stream areas of the Pearl River have become densely populated with intensive economic activities. Our study shows that in 2000 over half of DIN inputs to rivers of the down-stream and other sub-basins originated from anthropogenic sources. This was different in 1970, when only in the Xijiang and Zhujiang delta sub-basins more than half of the DIN inputs to rivers can be considered anthropogenic (maps in Figure 2).

Between 2000 and 2050 DIN inputs from land to rivers of the sub-basins may continue to increase. These inputs will mainly be from anthropogenic sources, except for the Yujiang (see maps in Figure 2). For the Yujiang sub-basin, we calculate a decrease in DIN inputs from agriculture (but not from sewage), but an increase in DIN inputs from non-anthropogenic sources. A possible reason for this may be a decline in agricultural areas in the coming decades [11]. As a result of increased DIN inputs to rivers, DIN fluxes to coastal waters may increase by up to 30\% during the period 2000-2050 (bar charts in Figure 2). These results are for a scenario assuming a globalising world and a reactive approach towards environmental management. Anthropogenic sources may contribute by $90 \%$ to the total DIN inputs in the coastal waters in 2050 (Figure 2).

\subsection{DIP export}

DIP inputs to coastal waters of the Pearl River were $45 \%$ higher in 2000 $\left(0.010\right.$ ton $\left.\mathrm{km}^{-2}\right)$ than in $1970\left(0.006\right.$ ton $\left.\mathrm{km}^{-2}\right)$ (bar charts in Figure 3).

Human activities are the main reason for this increase. Anthropogenic sources of DIP include sewage inputs of human waste and detergents (point sources), 


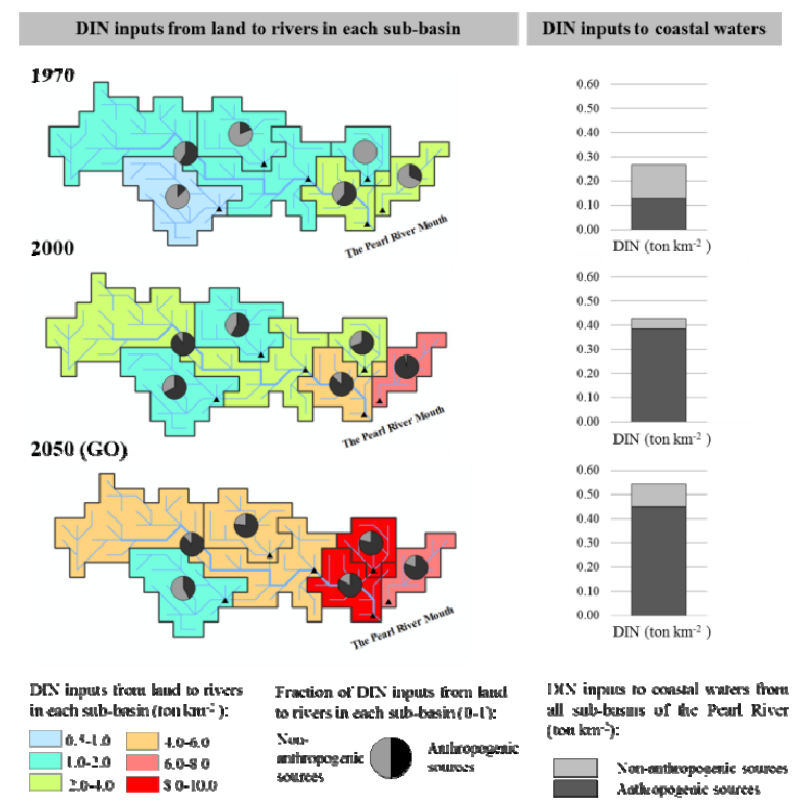

Figure 2: Dissolved inorganic nitrogen (DIN) inputs from land to rivers in each sub-basin in ton $\mathrm{km}^{-2}$ (maps on the left-hand side) and the fraction of these inputs originating from anthropogenic and nonanthropogenic sources (pie charts on the maps, 0-1), and DIN inputs exported by the Pearl River to coastal waters from all subbasins in ton $\mathrm{km}^{-2}$ (bar charts on the right-hand side) for 1970, 2000 and 2050. GO is the Global Orchestration scenario of the Millennium Ecosystem Assessment. See Figure 1 for sub-basin names. Anthropogenic diffuse sources include animal manure excretion, synthetic fertilizer use, biological $\mathrm{N}_{2}$-fixation by agricultural crops, and atmospheric $\mathrm{N}$-deposition on agricultural land. Anthropogenic point sources include human waste. Nonanthropogenic sources include biological $\mathrm{N}_{2}$-fixation and atmospheric N-deposition on non-agricultural areas.

animal manure excretion, synthetic fertilizers use, P-weathering in agricultural areas (diffuse sources). These sources were major contributors to DIP in rivers in all sub-basins in 2000 (maps in Figure 3). And this explains their major contribution to DIP fluxes at the coastal waters (bar charts in Figure 3).

In general, DIP inputs from land to rivers in the down-stream sub-basins are higher compared to the other sub-basins. This can be explained by the relatively large percentage of the population that is connected to sewage systems [12]. Increased sewage connection means that more phosphorus may enter rivers, even in case sewage treatment is efficiently removing DIP from sewage effluents. Several studies $[24,26,42,43]$ confirm the fast economic development in the 


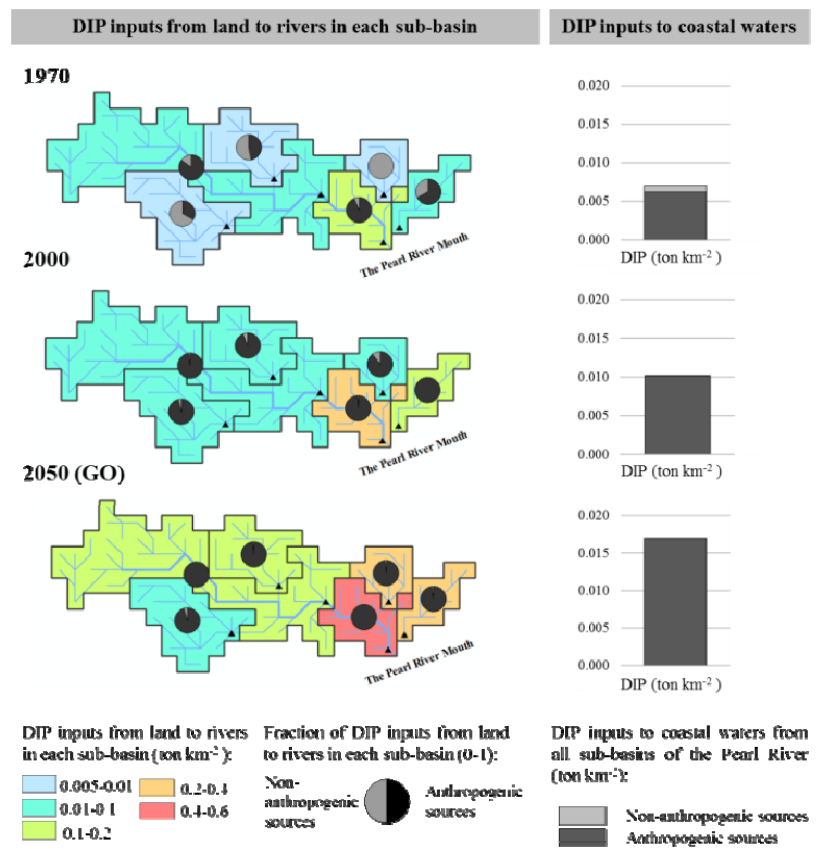

Figure 3: As Figure 2 but for dissolved inorganic phosphorus (DIP). Anthropogenic diffuse sources include animal manure excretion, synthetic fertilizer use and P-weathering in agricultural areas. Anthropogenic point sources include sewage inputs of human waste and detergents. Non-anthropogenic sources include P-weathering in non-agricultural areas.

down-stream areas of the Pearl River, as a result of which large amounts of nutrients have entered the estuary of the Pearl River during the past decades.

In the future, the DIP exported to the coastal waters by the Pearl River is calculated to be largely anthropogenic (Figure 3). We calculate an increase in river export of DIP of about $70 \%$ at the Pearl River mouth between 2000 and 2050 (bar charts in Figure 3). DIP inputs from land to rivers are calculated to increase in all sub-basins between 2000 and 2050 (maps in Figure 3). For example, DIP inputs to rivers in the Zhujiang delta and Dongjiang may double during this period. For the Beijiang sub-basin, DIP inputs to rivers are calculated to increase from 0.04 ton $\mathrm{km}^{-2}$ in 2000 to 0.28 ton $\mathrm{km}^{-2}$ in 2050 . In the other subbasins, DIP inputs to rivers are calculated to triple except for the Yujiang (for which a doubling is calculated) (maps in Figure 3). Anthropogenic sources are responsible for these increases (pie charts on maps in Figure 3).

\section{Conclusions}

Eutrophication in the Chinese seas is a result of increased nutrient export by large rivers such as the Pearl River (Zhujiang in Chinese). We modelled the 
relative contributions of the main sources of dissolved inorganic $\mathrm{N}$ (DIN) and $\mathrm{P}$ (DIP) in the Pearl River for the period 1970-2050. Our model takes into account sub-basin characteristics like human activities on land (e.g. agriculture, sewage) and nutrient retentions in soils and in river systems.

Our study shows that DIN and DIP export to the coastal waters of the Pearl River increased by $60 \%$ for DIN and by $45 \%$ for DIP between 1970 and 2000 and may continue increasing in the future. Various anthropogenic sources contribute to these increases (e.g. agriculture, sewage, atmospheric N-deposition, biological $\mathrm{N}_{2}$-fixation by agricultural crops, and $\mathrm{P}$-weathering in agricultural areas). Anthropogenic sources of DIN and DIP dominate in most of the subbasins.

In 1970 non-anthropogenic sources (atmospheric N-deposition and biological $\mathrm{N}_{2}$-fixation by natural vegetation in non-agricultural areas) contributed by about half to the DIN export to the coastal waters, but this has been changing over time. By 2000 almost $90 \%$ of the total DIN inputs to the coastal waters were from anthropogenic sources (e.g. agriculture, sewage, atmospheric N-depositions and biological $\mathrm{N}_{2}$-fixation by agricultural crops on agricultural land). In contrast with DIN, in 1970 most DIP in the Pearl River was from anthropogenic sources (sewage, agriculture, P-weathering over agricultural areas). By 2000 the anthropogenic contribution increased.

Between 2000 and 2050 the export of anthropogenic DIN and DIP by the Pearl River to coastal waters may further increase. This is associated with increased anthropogenic DIN and DIP inputs from land to rivers in the subbasins. These results indicate that in the future human activities on land will still dominate DIN and DIP in the river water, unless nutrient management (e.g. efficient use of fertilizers, better sewage treatment) will effectively reduce $\mathrm{N}$ and $\mathrm{P}$ inputs to the river.

This study is a first step towards identifying the main sources of DIN and DIP in the Pearl River water by considering sub-basin characteristics. We show that down-stream sub-basins have a larger impact on nutrient inputs to coastal seas than up-stream sub-basins. Future research could focus on analysing the contributions of anthropogenic sources to the river exports of DIN and DIP and the contributions of sub-basins to these exports. This will help to formulate strategies to reduce nutrient inputs to rivers by sub-basin so that nutrient inputs to the coastal waters can be reduced as well. This could consequently slow down the increase in future coastal eutrophication in southern China.

\section{References}

[1] Diaz, R.J., Overview of hypoxia around the world. Journal of environmental quality, 30, pp. 275-281, 2001.

[2] Diaz, R.J. \& Rosenberg, R., Spreading dead zones and consequences for marine ecosystems. Science, 321, pp. 926-929, 2008.

[3] Selman, M., Greenhalgh, S., Diaz, R. \& Sugg, Z., Eutrophication and hypoxia in coastal areas: a global assessment of the state of knowledge. World Resources Institute 284, 2008. 
[4] Liu, W. \& Qiu, R., Water eutrophication in China and the combating strategies. Journal of Chemical Technology and Biotechnology, 82, pp. 781-786, 2007.

[5] Wang, S., Tang, D., He, F., Fukuyo, Y. \& Azanza, R.V., Occurrences of harmful algal blooms (HABs) associated with ocean environments in the South China Sea. Hydrobiologia, 596, pp. 79-93, 2007.

[6] Garnier, J., Beusen, A., Thieu, V., Billen, G. \& Bouwman, L., N:P:Si nutrient export ratios and ecological consequences in coastal seas evaluated by the ICEP approach. Global Biogeochemical Cycles, 24, GB0A05, 2010.

[7] Glibert, P.M., Burkholder, J.M., Graneli, E. \& Anderson, D.M. Advances and insights in the complex relationships between eutrophication and HABs: Preface to the special issue. Harmful Algae, 8, pp. 1-2, 2008.

[8] Heisler, J., Glibert, P.M., Burkholder, J.M., Anderson, D.M., Cochlan, W., Dennison, W.C., Dortch, Q., Gobler, C.J., Heil, C.A. \& Humphries, E., Eutrophication and harmful algal blooms: a scientific consensus. Harmful Algae, 8, pp. 3-13, 2008.

[9] Sutton, M.A., et al., Our Nutrient World: The challenge to produce more food and energy with less pollution, Global Overview of Nutrient Management. Centre for Ecology and Hydrology, Edinburg on behalf of the Global Partnership on Nutrient Management and the International Nitrogen Initiative, 2013.

[10] Seitzinger, S.P., Mayorga, E., Bouwman, A.F., Kroeze, C., Beusen, A.H.W., Billen, G., Van Drecht, G., Dumont, E., Fekete, B.M., Garnier, J. \& Harrison, J.A., Global river nutrient export: A scenario analysis of past and future trends. Global Biogeochemical Cycles, 24, GB0A08, 2010.

[11] Bouwman, A.F., Beusen, A.H.W. \& Billen, G., Human alteration of the global nitrogen and phosphorus soil balances for the period 1970-2050. Global Biogeochemical Cycles, 23, GB0A04, 2009.

[12] Van Drecht, G., Bouwman, A.F., Harrison, J. \& Knoop, J.M., Global nitrogen and phosphate in urban wastewater for the period 1970 to 2050. Global Biogeochemical Cycles, 23, GB0A03, 2009.

[13] Zhou, T., Wu, J. \& Peng, S., Assessing the effects of landscape pattern on river water quality at multiple scales: A case study of the Dongjiang River watershed, China. Ecological Indicators, 23, pp. 166-175, 2012.

[14] Ju, X.T, Xing, G.X., Chen, X.P., Zhang, S.L., Zhang, L.J., Liu, X.J., Cui, Z.L., Yin, B., Christie, P. \& Zhu, Z.L., Reducing environmental risk by improving $\mathrm{N}$ management in intensive Chinese agricultural systems. Proceedings of the National Academy of Sciences, 106, pp. 3041-3046, 2009.

[15] Ma, L., Velthof, G.L., Wang, F.H., Qin, W., Zhang, W.F., Liu, Z., Zhang, Y., Wei, J., Lesschen, J.P., Ma, W.Q., Oenema, O. 7 Zhang, F.S., Nitrogen and phosphorus use efficiencies and losses in the food chain in China at regional scales in 1980 and 2005. The Science of the total environment, 434, pp. 51-61, 2012. 
[16] Liu, S.M., Li, L.W., Zhang, G.L., Liu, Z., Yu, Z. \& Ren, J.L., Impacts of human activities on nutrient transports in the Huanghe (Yellow River) estuary. J Hydrol, 430, pp. 103-110, 2012.

[17] Maimaitiming, A., Xiaolei, Z. \& Huhua, C., Urbanization in Western China. Chinese Journal of Population Resources and Environment, 11, pp. 79-86, 2013.

[18] Vitousek, P.M., Naylor, R., Crews, T., David, M., Drinkwater, L., Holland, E., Johnes, P., Katzenberger, J., Martinelli, L. \& Matson, P., Nutrient imbalances in agricultural development. Science, 324, p. 1519, 2009.

[19] Ma, L., Ma, W., Velthof, G., Wang, F., Qin, W., Zhang, F. \& Oenema, O., Modeling nutrient flows in the food chain of China. Journal of environmental quality, 39, pp. 1279-1289, 2010.

[20] Aregay, F.A. \& Minjuan, Z., Impact of Irrigation on Fertilizer Use Decision of Farmers in China: A Case Study in Weihe River Basin. Journal of Sustainable Development, 5, p. 74, 2012.

[21] Qu, H.J. \& Kroeze, C., Past and future trends in nutrients export by rivers to the coastal waters of China. The Science of the total environment 408, pp. 2075-2086, 2010.

[22] Qu, H.J. \& Kroeze, C., Nutrient export by rivers to the coastal waters of China: management strategies and future trends. Regional Environmental Change, 12, pp. 153-167, 2012.

[23] Weng, Q., A historical perspective of river basin management in the Pearl River Delta of China. Journal of environmental management, 85, pp. 10481062, 2007.

[24] Huang, X., Huang, L. \& Yue, W., The characteristics of nutrients and eutrophication in the Pearl River estuary, South China. Marine Pollution Bulletin, 47, pp. 30-36, 2003.

[25] Hu, J. \& Li, S., Modeling the mass fluxes and transformations of nutrients in the Pearl River Delta, China. Journal of Marine Systems, 78, pp. 146167. 2009.

[26] Zhang, J., Yu, Z., Wang, J., Ren, J., Chen, H., Xiong, H., Dong, L. \& Xu, W., The subtropical Zhujiang (Pearl River) estuary: nutrient, trace species and their relationship to photosynthesis. Estuar. Coast. Shelf Sci., 49, pp. 385-400, 1999.

[27] Zhang, J., Nutrient elements in large Chinese estuaries. Continental Shelf Research, 16, pp. 1023-1045, 1999.

[28] Zhang, S.R., Lu, X.X., Higgitt, D.L., Chen, C.TA., Sun, H.G. \& Han, J.T., Water chemistry of the Zhujiang (Pearl River): Natural processes and anthropogenic influences. Journal of Geophysical Research, 112, F01011, 2007.

[29] Zhang, Q., Xu, C.Y. \& Zhang, Z., Observed changes of drought/wetness episodes in the Pearl River basin, China, using the standardized precipitation index and aridity index. Theoretical and applied climatology, 98, pp. 89-99, 2009. 
[30] Cui, W.Z., Chen, J., Wu, Y.P. \& Wu, Y.D., An overview of water resources management of the Pearl River. Water Science \& Technology: Water Supply, 7, p. 101, 2007.

[31] Niu, J. \& Chen, J., Terrestrial hydrological features of the Pearl River basin in South China. Journal of Hydro-environment Research, 4, pp. 279-288, 2010.

[32] Liu, S., Hong, G., Zhang, J., Ye, X. \& Jiang, X., Nutrient budgets for large Chinese estuaries. Biogeosciences, 6, pp. 2245-2263, 2009.

[33] Vörösmarty, C., Fekete, B., Meybeck, M., \& Lammers, R., Global system of rivers: Its role in organizing continental land mass and defining land-to-ocean linkages. Global Biogeochemical Cycles, 14, pp. 599-621, 2000.

[34] Mayorga, E., Seitzinger, S.P., Harrison, J.A., Dumont, E., Beusen, A.H.W., Bouwman, A.F., Fekete, B.M., Kroeze, C. \& Van Drecht, G., Global Nutrient Export from WaterSheds 2 (NEWS 2): Model development and implementation. Environmental Modelling \& Software, 25, pp. 837-853, 2010.

[35] Dumont, E., Harrison, J.A., Kroeze, C., Bakker, E.J. \& Seitzinger, S.P., Global distribution and sources of dissolved inorganic nitrogen export to the coastal zone: Results from a spatially explicit, global model. Global Biogeochemical Cycles, 19, GB4S02, 2005.

[36] Meybeck, M. \& Ragu, A., River discharges to the oceans: An assessment of suspended solids, major ions and nutrients. UNEP, 1997.

[37] Fekete, B.M., Wisser, D., Kroeze, C., Mayorga, E., Bouwman, L., Wollheim, W.M. \& Vörösmarty, C., Millennium ecosystem assessment scenario drivers (1970-2050): climate and hydrological alterations. Global Biogeochemical Cycles, 24, GB0A12, 2010.

[38] Lehner, B., Liermann, C.R., Revenga, C., Vörösmarty, C., Fekete, B., Crouzet, P., Döll, P., Endejan, M., Frenken, K. \& Magome, J., Highresolution mapping of the world's reservoirs and dams for sustainable riverflow management. Front Ecol Environ, 9, pp. 494-502. 2011.

[39] Alcamo, J., Van Vuuren, D., Cramer, W., Alder, J., Bennett, E., Carpenter, S., Christensen, V., Foley, J., Maerker, M. \& Masui, T., Changes in ecosystem services and their drivers across the scenarios, Ecosystems and human well-being: Scenarios, pp. 297-373. 2005.

[40] Carpenter, S.R., Bennett, E.M. \& Peterson, G.D., Editorial: special feature on scenarios for ecosystem services. Ecol Soc, 11, p. 32. 2006.

[41] Lehner, B., Liermann, C.R., Revenga, C., Vörösmarty, C., Fekete, B., Crouzet, P., Döll, P., Endejan, M., Frenken, K. \& Magome, J., Global Reservoir and Dam (GRanD) database, 2011.

[42] Ma, J.T., Rural Industrialization, a Feasible Way towards Urbanisation in China. Advanced Materials Research, 598, pp. 193-201, 2012.

[43] Ho, K. \& Hui, K., Chemical contamination of the East River (Dongjiang) and its implication on sustainable development in the Pearl River Delta. Environment International, 26, pp. 303-308, 2001. 